\title{
肩関節石灰沈着例の臨床的検討
}

\author{
熊本県松橋療護園整形外科 \\ 井手 淳 二 \\ 熊本大学医学部整形外科 \\ 森 沢 佳 三・山 鹿 真紀夫 \\ 大平卓・北川敏夫
}

\section{Clinical Study on Shoulder Lesions with Calcification}

by

Junji Ide

Department of Orthopedic Surgery,

Kumamoto Matsubase Ryougoen

\section{Keizo Morisawa, Makio Yamaga, Takashi Ohira and Toshio Kitagawa \\ Department of Orthopedic Surgery, Kumamoto University Medical School, Kumamoto, Japan}

We studied 33 patients with calcification in the shoulder region clinically and radiologically. Six cases were male and 27 were female with the age ranged from 32 to 92 years old (average, $61.0 \pm 15.1$ years old). Four of the cases were bilateral, 17 were right sided and 12 were left sided.

According to the symptoms and the physical examinations, all patients were divided into three groups. 21 shoulders of 20 cases were classified as acute group, 12 shoulders of 11 cases as chronic or subacute group, and four shoulders of two cases as asymptomatic group.

The patients were evaluated with respect to roentgenographic patterns of calcification according to the following criteria :

Type 1 ; supraspinatus tendon (Seven shoulders).

Type 2 ; characterised by an elevation of the subacromial bursal floor, subbursal rupture or intrabursal rupture (20 shoulders).

Type 3 ; subscapularis tendon (Two shoulders).

Type 4 ; cartilage in the glenohumeral joint (Seven shoulders).

Type 5 ; characteristic large deposition around shoulder region (One shoulder).

The clinical diagnosis of the cases in Type $1 \sim 3$ was calcifying tendinitis, in Type 4 chondrocalcinosis and in Type 5 ectopic calcification associated with brain damage.

In acute group, $57 \%$ of the cases were treated by needling, $33 \%$ by conservative methods and $10 \%$ by operative methods. Needling was found more effective as compared to conservative methods. Patients treated by needling with steroid were not as quickly relieved from pain as those without steroid.

\section{はじめに}

屃関節およびその周囲組織に石灰化を起こす物質 として Hydroxyapatite (HA) 結晶, Calcium pyrophosphate dihydrate (CPPD) 結晶などが知られて おり,これらの沈着は急性および慢性炎症，また関節
破壊と関連を有することが示唆されている.

今回，我々は最近経験した肩関節に石灰沈着を来した 症例について検討を加え若干の知見を得たので報告する.

\section{対}

\section{象}

熊本大学整形外科および関連病院にて X線上肩関節 
に石灰沈着を認めた33例37肩を対象とした，男性 6 例 女性27例，平均年秢は61.0土15.1才であった。年代分 布を図 1 に示す.

症例数

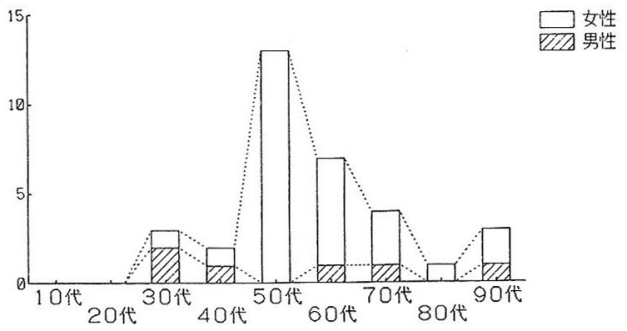

図1年代 分 布

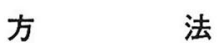

1 ）症状を病歴および理学的所見より急性型, 慢性一亜 急性型，無症状型に分類した。

急性痛風様発作で発症し，肩関節の運動制限が著名 で夜間痛が強い症例を急性型，比較的緩徐な発症で肩
関節の運動制限は少なく運動痛を主訴とする症例を慢 性一亜急性型とした9!.

2) X線学的には肩関節内旋・外旋 - 中間位前後像お よび軸射像に最大外転位, Y撮影を参考として石死沈 着部位, 変形性・破壊性変化について検討した。

石死沈着部位は, X 線上石灰陰影が長径 $8 \mathrm{~mm}$ 以下か つ短径 $3 \mathrm{~mm}$ 以下で棘上筋腱内に限局すると考えられる ものを Type 1, 長径 $8 \mathrm{~mm}$ 以上または短径 $3 \mathrm{~mm}$ 以上で 棘上筋腱あるいは棘下筋腱から肩峰下滑液包におよふ と考えられるものを Type 2，肩甲下筋にあると考え られるものを Type 3，関節軟骨にあるものを Type 4, 広範におよぶものを Type 5 と分類した.（図 2 ) 変形性変化については関節裂隙狭小化, 臼蓋緣の不 整・硬化像, 上腕骨解剖頸部の骨棘について検討した。 3 ）治療については, 罹病期間 - 治療法 - 症状軽快ま での期間を検討した。治療法は, 安静固定・投薬のみ の場合を保存療法, 穿刺吸引にステロイド剤注入を含 めて穿刺吸引療法とし，石兏摘出術を施行した場合を 手術療法とした.

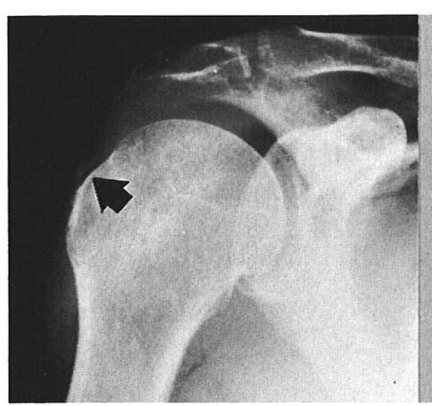

Type 1

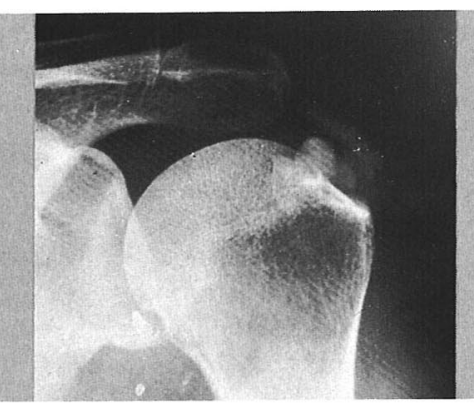

Type 2

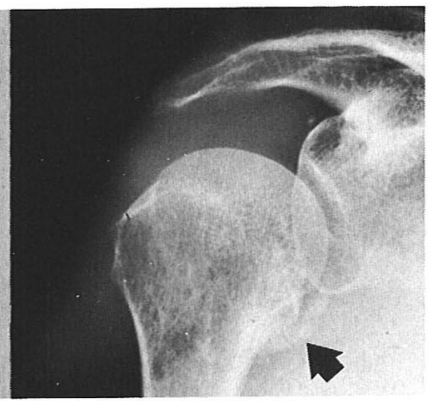

Type 3

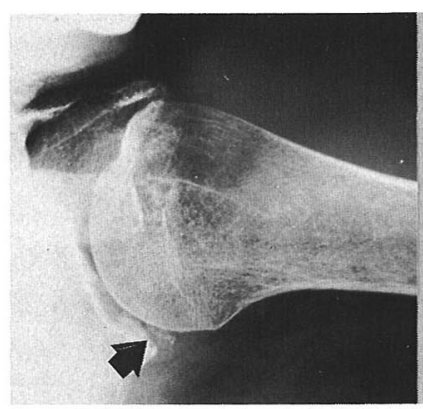

Type 4

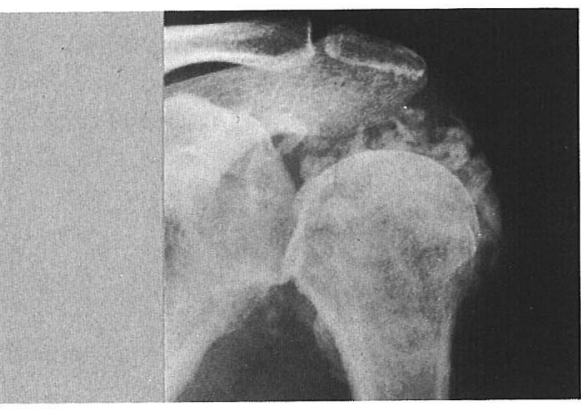

Type 5

図 2 石兏沈着部位分類 
結

\section{果}

1) 症状について

急性型は，20例21肩（全体の58.6\%）であり男性 1 例, 女性19例と圧倒的に女性に多かった. 右側例11肩, 左側例10肩であり左右差は無かった。平均年龄は, $58.1 \pm 9.7$ 才であった. 慢性〜亜急性型は, 11例12肩 (32.4\%) であり男性 5 例, 女性 6 例と性差はなく, 右 側例 8 肩, 左側例 4 肩と右側に多かった。平均年齢は, $60.6 \pm 17.8$ 才であった. 無症状型は 2 例 4 肩女性 2 例 で, 平均年秢は, 92.0 才であった。症状別年代分布を 図 3 に示す. 急性型は50代に多くいわ功五十肩の発 症年秢と一致していた。慢性〜亜急性型は各年代にほ ぼ均等に分布していた。

\section{2 ) X線学的検討}

石灰沈着部位を症状別に図 4 に示す. Type 1 系 で78.4\%を占めていた. Type 1 の約70\%は慢性〜亜 急性型であったのに対し Type 2 の90\%は急性型で あった. Type 5 の1例は，51才女性で脳損傷に伴う 異所性石灰化と考えられた症例であった。

肩関節の変形性変化を認めたものは 4 例 7 肩であり, 関節裂隙狭小化 4 肩, 臼蓋縁の不整・硬化像 6 肩, 上 腕骨解剖頸部の骨棘 4 肩であった。平均年齿は, 88.5 土6.1才と高踚の症例のみであった，石灰沈着部位は

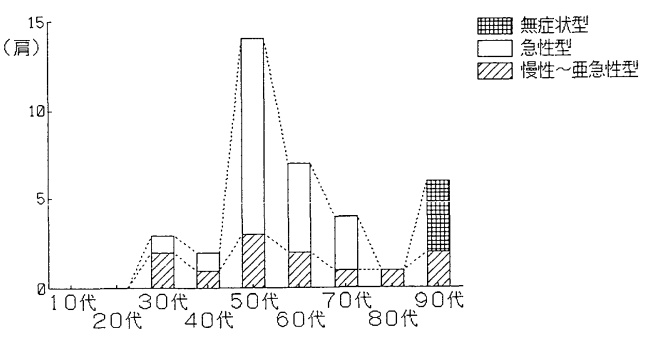

图 3 症状別年代分布

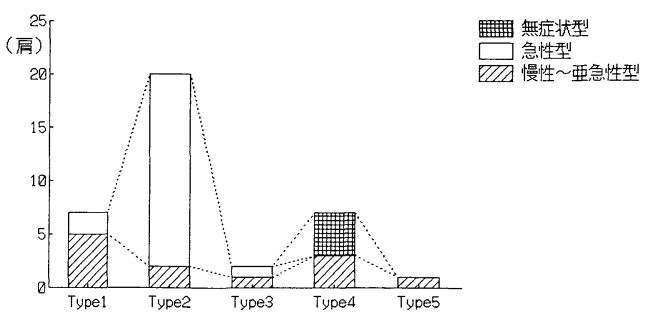

图 4 症状別石灰沈着部位
Type 4 が 6 肩 $(85.7 \%)$, Type 1, 1 肩であった. 破壊性変化を認める症例は無かった.

3 ）治療について

病歴の詳細な急性型14肩, 慢性一亜急性型 8 肩につ いて治療経過を検討した，急性型の場合，受診までの 期間は平均 $1.9 \pm 1.0$ 日でありほとんどの場合 3 日以内に 受診していた。慢性〜亜急性型の場合，平均罹病期間 は7.0士5.2力月であった。治療法を症状別に表 1 に示 す.いずれの場合も穿刺吸引療法が約60\%であった. 手術療法は, 保存療法および穿刺吸引療法が無効で あった急性型の 2 例と診断確定目的で慢性〜亜急性型 の Type 3 の1例に施行した. 症状軽快までの期間 は急性型では表 1 に示す如くであった，穿刺吸引療法 の方が症状軽快までの期間が短く，ステロイド剤は 7 肩に併用されていたが治療日数を短縮してはいなかった。

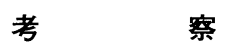

McCarty によると病的石灰化を起こす結晶は表 2 に示す如くである゙”. 石兏沈着性腱板炎は HA 結晶, 軟骨石灰化症は CPPD 結晶の沈着によるものが多い とされている゙1.

我々が今回検討した症例中, Type $1 \sim 3$ は臨床診 断名としては石灰沈着性腱板炎と考えられた．従来の 報告 ${ }^{5)}$ と同様に棘上筋腱周囲石灰沈着例が $93.1 \%$ と多 かった. Type $1 \sim 3$ 中 $72.4 \%$ が急性型であり年秢的 および性的素因が認められた。急性型はX $\mathrm{X}$ 線上 Type 2 , 即ち石灰沈着が局峰下滑液包におよぶと考えられ る像を $85.7 \%$ と高頻度に認めた。このことは急性疼痛 発作が石灰沈着の subbursal floor への irritation および肩峰下滑液包への波及によるという通説 ${ }^{3)}$ を支 持するものと考えられた。

Type 4 の 4 例はいずれも膝関節穿刺液より補正偏 光顕微鏡検査にて CPPD 結晶を認めており, 軟骨石 灰化症の一部分症状として肩関節軟骨石灰化を来した ものと考えられた. 緒方は CPPD 結晶沈着症は70才 以上に多く，その $42 \% に$ 肩関節軟骨の石兏沈着を認め たと報告している゙2. また，今回検討した 4 例には急性 型は無かったが, 外傷やストレスにより急性疼痛発作

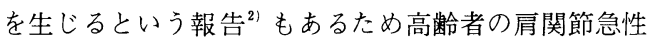
疼痛発作に対しては CPPD 結晶沈着症を念頭におく 必要があると思われた。

肩関節以外に股関節など多関節に石灰沈着を認めた 
表 1 症状別治療法

\begin{tabular}{c|c|c|c|c|c} 
& 保存療法 & 穿刺吸引療法 & 手術療法 & 不明 & 計 \\
\hline 急性型 & 7 & 12 & 2 & 0 & 21 \\
\hline 慢性 一亜急性型 & 3 & 4 & 1 & 4 & 12 \\
\hline 計 & 10 & 16 & 3 & 4 & 33 (肩)
\end{tabular}

表 2 症状軽快までの期間（急性型）

\begin{tabular}{|cr|}
\hline 保存療法 & $12.5 \pm 6.5$ 日 \\
穿刺吸引療法 & $3.7 \pm 2.1$ 日 \\
& $(\mathrm{P}<0.02)$ \\
\hline 穿刺吸引療法 & \\
steroid (+) & $4.0 \pm 2.2$ 日 \\
steroid (-) & $3.3 \pm 1.9$ 日 \\
& (N.S.) \\
\hline
\end{tabular}

表 3 Chemical Formulas and Molar Rations of Calcium to Phosphorus of Calcium-Containing Crystals

\begin{tabular}{|lll|}
\hline \multicolumn{1}{|c}{ Crystal } & \multicolumn{1}{c|}{ Formula } & \multicolumn{1}{c|}{$\mathrm{Ca} / \mathrm{P}$} \\
\hline Basic calcium phosphate (BCP) & & \\
Hydroxyapatite (HA) & $\mathrm{Ca}_{5}\left(\mathrm{PO}_{4}\right)_{3} \mathrm{OH} 2 \mathrm{H}_{2} \mathrm{O}$ & 1.67 \\
Octacalcium phosphate (OCP) & $\mathrm{Ca}_{8} \mathrm{H}_{2}\left(\mathrm{PO}_{4}\right)_{6} 5 \mathrm{H}_{2} \mathrm{O}$ & 1.33 \\
Tricalcium phosphate (TCP) & $\mathrm{Ca}_{3}\left(\mathrm{PO}_{4}\right)_{2}$ & 1.5 \\
OTHER & & \\
Dicalcium phosphate dihydrate & $\mathrm{CaHPO}_{4} 2 \mathrm{H}_{2} \mathrm{O}$ & 1.0 \\
Calcium pyrophosphate dihydrate & $\mathrm{Ca}_{2} \mathrm{P}_{2} \mathrm{O}_{7} 2 \mathrm{H}_{2} \mathrm{O}$ & 1.0 \\
Calcium oxalate & $\mathrm{CaC}_{2} \mathrm{O}_{4} \mathrm{H}_{2} \mathrm{O}$ & $\infty$ \\
\hline
\end{tabular}

表 4 Basic Calcium Phosphate (BCP) Crystal Assosiated Joint Disease

$\underline{\text { Calcific Periarthritis }}$

Unifocal

Multifocal

Familial

Calcific Tendonitis and Bursitis

Intra-articular BCP Arthropaties

Acute (Gout-like) attacks

Milwaukee shoulder/knee syndrome

(Large joint lysis; cuff tear arthropaty)

Erosive polyarticular disease

Mixed crystal deposition disease (BCP + CPPD)

Secondary BCP Crystal Arthropaties/Periarthropathies

Chronic renal failure

Collagen disease (calcinosis)

Sequel to neurologic injury

Post local corticosteroid injection

Other

Tumoral Calcinosis

Hyperphosphatemic

Nonhyperphosphatemic
症例が 5 例ありこれらは石灰沈着症を全身疾患の部分 症状として検索する重要性を示唆する症例であった"7.

我々が今回検討した症例中, Type 5 の 1 例は 51 才 女性で頭部外傷後植物人間となり, 受傷 6 力月後の X線像にて肩関節に石灰沈着を認めたものである. 中 枢神経損傷に伴う異所性石灰化と考えられた．この場 合の結晶も BCP 結晶であり (表 4$)^{4}$ ），その原因とし て年䊀・外傷性血腫・重症感染・患肢固定 - 交感神経 失調などの要因がこれまで示唆されているが，いまだ 不明である6.

治療に関しては急性型の場合，ステロイド剤は穿刺 吸引のみの場合と比較して症状回復期間を短縮してい なかった。 また，石灰吸収抑制 ${ }^{8}$, 筋萎縮 ${ }^{9}$, 結晶誘発 性炎症 ${ }^{11}$ などの危険性があるためその使用は慎重を要 する.

\section{結語}

1 ）肩関節に石灰沈着を認めた 33 例37肩（男性 6 例, 女性27例, 平均年秢 $61.0 \pm 15.1$ 才）の臨床症状・X線 的特徴・治療について検討した.

2) X線上，石灰沈着部位を 5 Type に分類した. Type $1 \sim 3$ は臨床的には石灰沈着性腱板炎であり全 
体の約80\%であった.このうち約70\%は急性型であり 50 代以上の女性に多く石灰沈着部位は Type 2 が85.7 \%を占めていた。

3 ）軟骨石兏化症と考えられた Type 4 は 4 例 7 肩で あり80代以上の高秢者に認められ，変形性変化を来し た症例を $85.7 \%$ と高率に認めた.

4) Type 5 の1例は中枢神経損傷に伴う異所性石兏 化と考えられた。

5 ）急性型の治療に関しては，穿刺吸引のみの場合と 比較してステロイド剤を併用しても症状回復期間は変 わらなかった.

（稿を終えるにあたり，症例を提供していただいた大 平修先生, 緒方正光先生, 竹野正幸先生に深謝致し ます.)

\section{参 考 文 献}

1) DePalma, A.F.: Surgery of the shoulder, $3 \mathrm{rd}$ ed., J.B.Lippincott, Philadelphia, 1983.

2）石川浩一郎：軟骨石灰化症と結晶誘発性炎症. 整形 外科, 37：505-518，1986.

3) McCarty, D.C.: Arthritis and Allied Conditions, 10 th ed., Lea \& Febiger, Philadelphia, 1985.

4) Mosely, H.F.: Shoulder lesions. 3rd ed.,Churchill
Livingstone, Edinburgh and London, 1972.

5) 緒方正光:Calcium Pyrophosphate Dihydrate Crystal Deposition Disease の臨床的研究, 日整会 誌, $59 ： 819-834,1985$.

6) Rosin, A.J.: Ectopic calcification around joints of paralysed limbs in hemiplegia, diffuse brain damage, and other neurological diseases, Ann. rheum. Dis., 34: 499-505, 1975.

7）高岸直人：関節周囲急性石灰沈着症, 整形外科と災 害外科, $11: 30-33,1962$.

8）渡辺 晋：肩関節の症候性石灰沈着に対する乱刺 · 吸引法の適応について, 肩関節, 8:73-77, 1984.

9）山路兼生：腱板炎の治療 《とくに石灰沈着症につい て》, 別冊整形外科, 肩関節, $6: 58-60,1984$.

\section{質 問}

石死沈着性腱板炎・軟骨石兏化症など違う entityの 疾患が含まれている様ですが......?

\section{解 答熊本県松橋療護園 井手 淳二}

石死沈着性腱板炎は HA 結晶, 軟骨石疢化症は CP $\mathrm{PD}$ 結晶の沈着によるものが多いとされています。今 回，これらを結晶誘発性炎症という概念のもとに，ま とめてX線上肩関節に石灰沈着をきたした症例を検討 致しました。 